2018-08

\title{
Fatigue Properties and Fracture
}

Morphology of Micronised Rubber

Powder (MRP) from Waste Tyres in

\section{Unfilled Elastomers}

\author{
Habibah A.I.H., D
}

http://hdl.handle.net/10026.1/11429

10.18178/ijmmm.2018.6.4.392

International Journal of Materials, Mechanics and Manufacturing IACSIT Press

All content in PEARL is protected by copyright law. Author manuscripts are made available in accordance with publisher policies. Please cite only the published version using the details provided on the item record or document. In the absence of an open licence (e.g. Creative Commons), permissions for further reuse of content should be sought from the publisher or author. 


\title{
Fatigue Properties and Fracture Morphology of Micronised Rubber Powder (MRP) from Waste Tyres in Unfilled Elastomers
}

\author{
Dayang Habibah A. I. H, Frank Abraham, John Summerscales, and Paul Brown
}

\begin{abstract}
Ground rubber from waste tyres may be added to elastomers with economic and environmental benefits. The untreated or treated fillers have been investigated in different types of virgin rubber matrix. A principal concern is their crosslinked structure and large particle sizes. These additives introduce flaws leading to micro-crack initiation especially under dynamic loading. The incorporation of smaller particles at a suitable concentration may avoid deterioration in the key properties.

The present work studies the effect of commercial cryogenic micronised rubber particle (MRP) (apparent particle size diameter less than $100 \mu \mathrm{m}$ ) as filler at either 10 or 30 parts per hundred rubber (pphr) on the fatigue properties of natural rubber (NR), butadiene rubber (BR) or NR/BR blends (without carbon black in the host matrix). In non-crystallising rubber, BR compound containing MRP shows an enhancement in the fatigue properties. However, in NR and NR/BR blends the fatigue properties are reduced. Scanning electron microscope (SEM) observations have been used to correlate the fatigue properties with the morphology of the fracture surfaces. For NR or higher ratio of NR matrix, a scale-like texture dominated the fatigue behaviour of the compound. The fracture surface of MRP-filled compound had increased surface roughness compared to their control compound.
\end{abstract}

Index Terms-Elastomer, fatigue properties, fatigue fracture morphology, micronised rubber powder, unfilled.

\section{INTRODUCTION}

It is estimated that 800 million tyres are discarded annually around the world and this figure is expected to increase by $2 \%$ every year [1], [2]. Elsewhere, statistics indicating over one billion waste tyres generated per year have been reported [3], [4]. Therefore, over the past few years and still of interest, countless studies and materials characterisation on waste rubber tyres in thermoplastic, thermosets, blends were published. Despite the difficulties faced by the rubber industries in obtaining of the best method of recycling, research on waste tyres persists seeking to realise both

Manuscript received October 12, 2017; revised January 18, 2018. This work was supported by Malaysian Rubber Board.

Dayang Habibah A. I. H. is with the School of Engineering, University of Plymouth, Plymouth PL4 8AA, United Kingdom, on leave from the Malaysian Rubber Board, Selangor, Malaysia (e-mail: dyghabibah@gmail.com).

Frank Abraham and John Summerscales are with the School of Engineering, University of Plymouth, Plymouth PL4 8AA, United Kingdom (e-mail: frank.abraham@plymouth.ac.uk, J.Summerscales@plymouth.ac.uk).

Paul Brown is with Tun Abdul Razak Research Centre (TARRC), Malaysian Rubber Board, Brickendonbury, Hertford, SG13 8NL, United Kingdom (e-mail: PBrown@tarrc.co.uk). economic and environmental benefits. The emergence of smaller sizes of recycled rubber powder in micronised form certainly has great potential in many applications. Ayyer and co-authors [5] investigated the effects of particle size of cryogenically-ground micronised rubber powder (MRP) on the properties of polypropylene-MRP compounds. They reported that the cryogenic particles had higher surface area due to higher content of finer particles compared to ambient particles at all the nominal particle sizes. Ambient particles are claimed to provide better mechanical properties compared to cryogenic filled particle compound due to the convoluted structure. Nonetheless, the commercial scale process for ambient ground rubber is only able to produce $\geq 400 \mu \mathrm{m}$ particles.

Although many studies involved recycled rubber materials, only quasi-static mechanical properties are reported. Little work relates the fatigue properties and fracture morphology. The aim of this paper is to investigate the effect of smaller recycled particle sizes as opposed to the common sizes used $(\sim 400 \mu \mathrm{m})$ in rubber compound. The effect of adding commercial MRP $(\sim 74 \mu \mathrm{m}$ particle size $)$ from cryogenic processes, at 10 and $30 \mathrm{pphr}$, on fatigue properties and morphology of un-filled natural rubber (NR)/butadiene rubber (BR) blends at 70/30 ratio was studied. This ratio was selected due to a suitable blend composition for a typical truck tyre formulation. When it comes to high value product under dynamic conditions, the effect during service cannot be compromised. Hence, there is an impetus to study the fatigue properties of rubber compound containing recycled powder made from waste tyres. Fatigue properties for unfilled individual NR and BR were also investigated for comparison.

\section{EXPERIMENTAL}

\section{A. Materials}

The rubber matrix was NR, BR compound and NR/BR blend systems (70/30 ratio). Micronised rubber powder (MRP-Polydyne $\left.{ }^{\mathrm{TM}} 200\right)$ from truck tyre, 200 mesh $(74 \mu \mathrm{m})$ were supplied by Lehigh Technologies of Georgia, US. Natural rubber was Standard Malaysian Rubber (SMR) 10 and BR was cis-1, 4 polybutadiene rubber (Europrene Neo cis-BR-40). Chemical ingredients as defined in Table I were commercial grades and used without purification. The curatives, 1.2 parts per hundred rubber (pphr) sulphur and 1pphr TBBS (N-tert-butyl-2-benzothiazole sulphenamide) were added during final mixing. All rubber and chemical ingredients were supplied by Tun Abdul Razak Research Centre (TARRC). 


\section{B. Mixing and Preparation}

NR was masticated to reduce the viscosity to a nominal range of 60 units $\left(\mathrm{ML}(1+4)\right.$ at $\left.100^{\circ} \mathrm{C}\right)$, using cracker mill and a two-roll mill. Two master batches of each compound were prepared using Polylab 2000E internal mixer with Banbury rotors $\left(390 \mathrm{~cm}^{3}\right.$ and fill factor of 0.75$)$. The mixing of the masterbatch was carried out with starting temperature of $40^{\circ} \mathrm{C}$ and rotor speed of $80 \mathrm{rpm}$. The total mixing time was about 5 $\mathrm{min}$. The master batches were allowed to cool down overnight and cross-blended using a two-roll mill before the addition of the curatives. The samples were compression-moulded into $229 \mathrm{~mm}$ square sheets of $2 \mathrm{~mm}$ thickness and vulcanised in a press at $160^{\circ} \mathrm{C}$ to their respective optimum cure time, $t_{95}$. Hardness button, which is a cylindrical disc of $25 \mathrm{~mm}$ diameter and $6 \mathrm{~mm}$ thickness, was cured at $t_{95}+5$ mins.

TABLE I: RUBBER FORMULATION CONTAINING RECYCLED RUBBER POWDER (PPHR)

\begin{tabular}{lccc}
\hline Masterbatch & 0 & 10-MRP & 30-MRP \\
\hline \hline Rubber (NR, BR or NR/BR blends & 10 & 100 & 100 \\
(70/30 ratio) & 0 & & \\
Zinc Oxide & 3.5 & 3.5 & 3.5 \\
Stearic Acid & 2.5 & 2.5 & 2.5 \\
Antilux 654 wax & 1 & 1 & 1 \\
6PPD antioxonant & 2.5 & 2.5 & 2.5 \\
Flectol TMQ antioxidant & 1 & 1 & 1 \\
MRP (micronised) & 0 & 10 & 30 \\
\hline \hline
\end{tabular}

6PPD: N-1,3-dimethylbutyl-N' phenyl-p-phenylenediamine

TMQ: 2,2,4-trimethyl-1,2-dihydroquinoline

\section{Mechanical Properties}

The tensile properties were determined according to BS ISO 37:2011 (Type 2 test pieces). An Instron 5567 universal testing machine was used with $1 \mathrm{kN}$ load cell operating at crosshead speed of $500 \mathrm{~mm} / \mathrm{min}$. Hardness measurement in Shore A was in accordance to BS ISO 7619-1:2010. The median of five readings, as required by the standard, were also recorded from tensile test and two hardness buttons from each compound.

\section{Fatigue Testing}

Eight tensile dumbbells (BS ISO 37:2011 Type 2 test pieces) were cut from each cured sheet. Two test pieces were used for the setup. The test pieces were each marked with a 20 $\mathrm{mm}$ gauge length on the narrow part. The setup is shown in Fig. 1 and each station attached to a $100 \mathrm{~N}$ load cell. A Labview-based system records all the load cell data. Linear Variable Differential Transformers (LVDT) were also used to monitor displacement data as a function of time. More details of the testing machine layout was published by Kamaruddin [6]. The specimens were cycled at a frequency of $4.5 \mathrm{~Hz}$ to a maximum strain of $100 \%$ in marked gauge length until failure under fully relaxing conditions, i.e. minimum strain was zero, and the number of cycles to failure recorded. Median of the six measurements was reported.

\section{E. Particle Size, Morphology, and Characterisation of Fatigue Fracture Surfaces}

The morphology of the raw MRP, and fatigue fracture surface after fatigue testing, were observed using JEOL JSM-6610 Scanning Electron Microscope (SEM), operating at $15 \mathrm{kV}$ accelerating voltage. Fracture surface specimens were cut about $3 \mathrm{~mm}$ from the surface fracture and all specimens were gold coated prior to analysis to avoid electrical charging.

MRP particles size distribution was analysed using the (open source image analysis software by the US National Institute of Health, http://imagej.nih.gov/ij) ImageJ package. The image of MRP from SEM was transformed to binary image before the analysis was done. The analysis set 100 square microns as the particle lower limit area and assumed that the particles are round, the apparent average particle size diameter was calculated. Comparing the binary to the original image is important to avoid unnecessary stray pixels. Overlap particles need to be separated using watershed function by Image $\mathbf{J}$.

\section{F. Confocal Technique}

An Olympus LEXT/OLS 3000 Laser Scanning Confocal Microscope (LSCM) was used to examine the fatigue fracture surface of selected rubber compounds. LSCM can also reconstruct three-dimensional (3D) topography maps of the fracture surfaces of the rubber matrix. The technique used was confocal scanning mode at $50 \times$ magnification. The presence of a pinhole in the detection light path produces improved depth of focus relative to conventional microscopy [7]. Thus, reduction of the out-of-focus background from in-focus signal focal plane enables sharp images. The fatigue fracture sample from SEM observation was used for the 3D reconstruction.

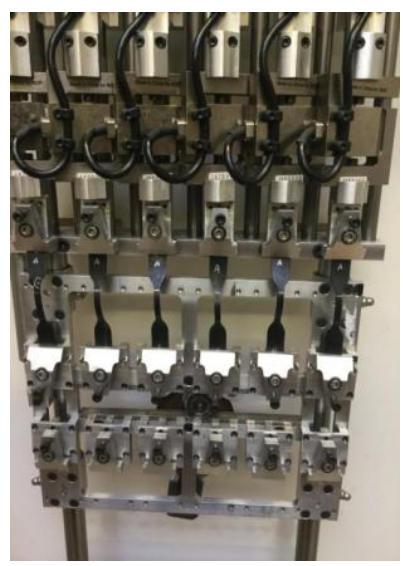

Fig. 1. Fatigue setup-up with samples at fully-relaxing conditions.

\section{RESULTS AND DISCUSSION}

\section{Characterisation of raw MRP:}
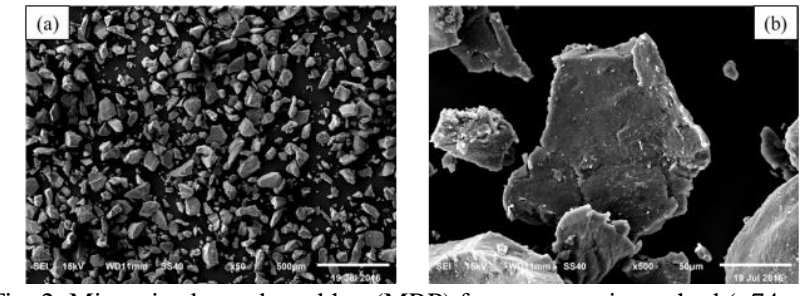

Fig. 2. Micronized powder rubber (MRP) from cyrogenic method $(\sim 74 \mu \mathrm{m})$, (a) white scale bar represents $500 \mu \mathrm{m}$ (b) white scale bar represents $50 \mu \mathrm{m}$.

Fig. 2 shows the morphology of MRP with nominal particle size of $74 \mu \mathrm{m}$ (Lehigh Technologies product specification). It is clear that the structure of cryogenic powder from waste tyres is smooth and angular, consistent with reports from other 
authors [5], [8]. Majority of the particles, that is about $48 \%$ fall between 30-60 $\mu \mathrm{m}, 26 \%$ between 60-90 $\mu \mathrm{m}, 20 \%$ between $0-30 \mu \mathrm{m}$ and $6 \%$ between $90-120 \mu \mathrm{m}$ as shown in Fig. 3 . The higher particle sizes range above $100 \mu \mathrm{m}$ probably due to the agglomeration or overlapping particles which is difficult to separate during image analysis measurement.

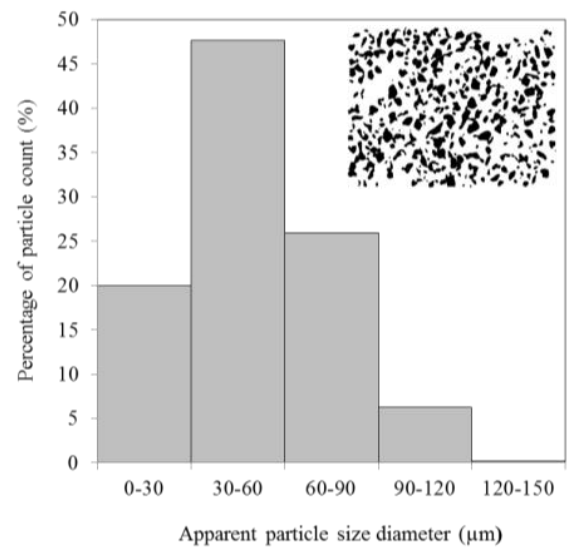

Fig. 3. Histogram of percentage particle count versus apparent particle size diameter $(\mu \mathrm{m})$.

\section{Mechanical properties:}

Table II summarises the mechanical properties of NR, BR and NR/BR containing MRP at 10 and $30 \mathrm{pphr}$. For NR, the addition of up to $30 \mathrm{pphr}$ of MRP slightly decreases the tensile strength. This is expected as the MRP could act as a critical stress-raiser that initiates fracture and lowers the strength [9]. The tensile strength of unfilled BR is very low. In contrast with NR, the addition of finer particles size increases the tensile strength of BR compound slightly. The MRP particles could probably link the BR matrix as a continuous matrix structure which resulted in an improvement in the tensile properties. Introduction of BR into NR compound slightly reduces the tensile properties of the rubber. In NR/BR compound, MRP-filled at 10 or $30 \mathrm{pphr}$ exhibited higher tensile properties in comparison to the control compound. Nevertheless, failure at the machine grip for all the control samples indicates only a lower bound to tensile strength.

TABLE II: RubBER Formulation MECHANICAL PROPERTIES OF RUBBER

\begin{tabular}{|c|c|c|c|c|}
\hline \multicolumn{5}{|c|}{ CONTAINING MRP } \\
\hline & $\begin{array}{l}\text { Tensile } \\
\text { strength } \\
(\mathrm{MPa})\end{array}$ & $\begin{array}{c}\text { Modulus } \\
(\mathrm{M} 100) \\
(\mathrm{MPa})\end{array}$ & $\begin{array}{c}\text { Elongation } \\
\text { at break } \\
(\%)\end{array}$ & $\begin{array}{l}\text { Hardness } \\
\text { (Shore } \\
\text { A) }\end{array}$ \\
\hline NR/0 (control) & 26.2 & 0.62 & 790 & 32 \\
\hline NR/10-MRP & 19.7 & 0.64 & 750 & 34 \\
\hline NR/30-MRP & 18.3 & 0.71 & 670 & 36 \\
\hline BR/0 (control) & 1.6 & 0.92 & 290 & 41 \\
\hline BR/10-MRP & 2.0 & 0.89 & 335 & 41 \\
\hline BR/30-MRP & 3.3 & 0.86 & 460 & 40 \\
\hline $\begin{array}{l}\text { NR/BR/0 } \\
\text { (control) }\end{array}$ & $14.2^{*}$ & 0.76 & 680 & 35 \\
\hline NR/BR/10-MRP & 16.7 & 0.71 & 750 & 36 \\
\hline NR/BR/30-MRP & 14.8 & 0.78 & 660 & 37 \\
\hline
\end{tabular}

The modulus at $100 \%$ elongation (M100) and hardness showed little change with the addition of $10 \mathrm{pphr}$ of MRP. The incorporation of $30 \mathrm{pphr}$ further increases the modulus and reduces the elongation at break (EB) for NR and NR/BR blends. In BR compound, the incorporation of MRP slightly reduces hardness and the modulus, but increases the EB. The sulphur migration from the virgin matrix to the recycled rubber powder, reported by Gibala and Hamed [10], slightly reduced the crosslinking density of the rubber hence permitting greater molecular chain mobility under tension. The reduction in crosslinking and smaller particles of MRP increases the tensile strength and contributes to the higher EB of BR compound.

For the addition of recycled rubber powder (RRP) content, modification of rubber formulation is also essential as Papp [4] found that increasing sulphur and slightly reduced accelerator improved the tensile strength of the compound. In addition, carbon black incorporation can also minimise the detrimental properties of compound containing RRP [11].

\section{Fatigue properties:}

Fig. 4 shows the fatigue life for unfilled NR, BR and NR/BR compound. The addition of up to $30 \mathrm{pphr}$ MRP to the BR compound seems to increase the fatigue life of the vulcanisates. The increase in fatigue life for BR containing larger quantities of MRP could be explained by the continuous structure of BR containing MRP particles which contributed to better fatigue properties. These results also showed that the MRP particles are well-bonded in the BR matrix.

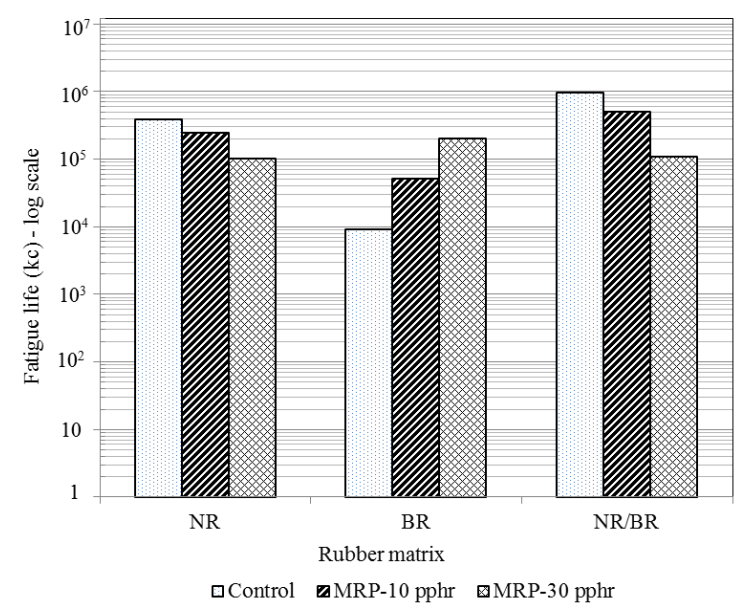

Fig. 4. Fatigue properties of NR, BR and NR/BR containing MRP at 0, 10 and $30 \mathrm{pphr}$ filler loadings.

In NR and NR/BR, the opposite trend to BR compound was observed. Increasing concentration of $30 \mathrm{pphr}$ further deteriorates the fatigue properties of MRP-filled NR and the blends compound. The fatigue lives of the compound containing $30 \mathrm{pphr}$ are approximately one third of those for the NR and much lower for NR/BR control compound. The reduction of fatigue properties is in agreement with another study for inclusion of recycled rubber material [12]. The fatigue life of this compound can be compensated by carbon-black filler and further improved by adjusting the crosslinking systems. These results also showed the benefit of blending where the fatigue of NR was enhanced with partial replacement of BR.

\section{Surface morphology of fatigue fracture samples:}

The SEM images of NR, BR and NR/BR vulcanisates after fatigue failure are shown in Fig. 5. There are different textures in surface fracture between MRP-filled and their control compounds. NR control compound, showed two distinct phases (rough and smooth surfaces) which probably represent 
two different failure morphologies, indicated as region I and II in Fig. 5(a). The rough phase (I) textures consist of multiple layer of cracks. Stéphanie et al. [13] relate the fracture "leaves" as the secondary crack branching during fatigue crack propagation for carbon black filled NR. The fracture 'leaves' or scale-like textures provide a greater resistance to the dynamic load which support the fatigue life result (Fig. 4). Munoz et al. [14] have reported that the crack growth velocities are well connected to the fracture morphology. It is believed that the fracture starts from region 'I', which indicates a low velocity of crack growth. As the crack progresses, at a certain stage the stress distribution in the matrix is no longer uniform and cannot arrest the crack propagation. Hence, there is a transition between the two phases before tearing. The higher velocity of crack growth is believed to have occurred leading to catastrophic failure (region 'II') resulting in the formation of a relatively smoother failure surface.
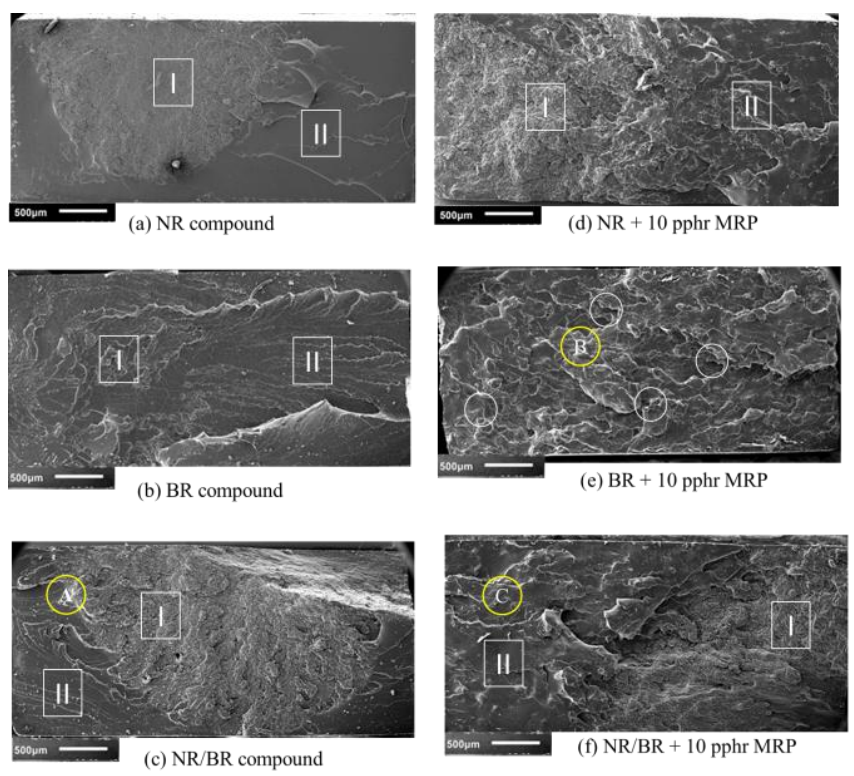

(I) Rough surfaces

(II) Smooth surfaces

Fig. 5. SEM micrograph of fatigue fracture surfaces of NR, BR and NR/BR containing 10 pphr of MRP.

In BR control compound, the rough surface region is less obvious. Overall, BR showed much smoother surfaces without the addition of the MRP. This texture shows that fracture easily occur across the BR matrix without considerable resistance which resulted in reduced number of fatigue cycles i.e. average value about 10,000 cycles at $100 \%$ strain. The topography map by confocal technique (Fig. 6 (a)) clearly indicates brittle structure where the cracks propagate through the matrix. Similar structure was observed as mud-cracks by Agarwal et al. [15] and also found for tensile fracture surface in unfilled ethylene-propylene rubber [16].

For NR/BR blends, a similar texture as in NR was observed. However, the proportion of 'I' largely dominates the surface failure compared to the NR compound. This observation supports the enhancement of fatigue life of NR/BR vulcanisates relative to individual NR compound. The 3-D topography image shown in Fig. 6 (b) displayed the transition from rough to smooth failure phase for NR/BR compound marked as A-section in Fig. 5(c). Uneven fracture planes are noticed, which correlate well to the 'scale-like' features.

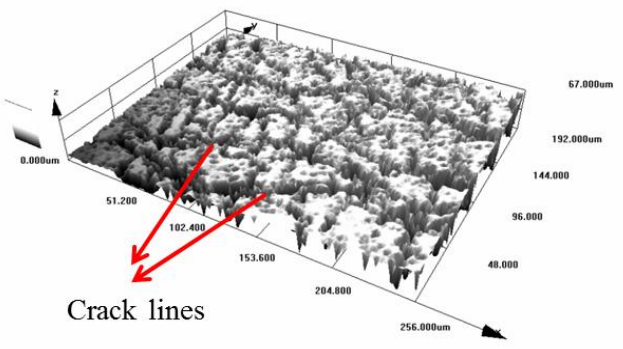

(a) BR compound

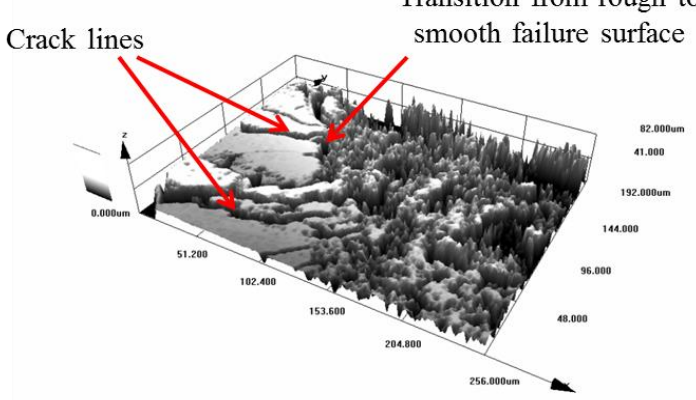

(b) NR/BR compound-transition phase

Fig. 6. 3-dimensional image construction of topography map of fatigue fracture surface of BR and NR/BR compound at a specific area.

The incorporation of $10 \mathrm{pphr}$ MRP in BR compound produced much rougher surfaces as designated by ' $\mathrm{B}$ ' compared to the control compound. More fracture "leaves" and distinct disordered crack lines are observed which are indicated by the circles (Fig. 5(e)). It is believed that the cracks are deflected by the recycled particles into the rougher regions surrounding them. Clearly, the crack deflection is responsible for the increase of surface roughness. MRP-filled BR showed homogenous and more consistent roughness to support the result that the addition of MRP improved the fatigue life of BR compounds.

In NR and NR/BR blends containing $10 \mathrm{pphr}$ of MRP, the rough surface morphology region tends to decrease. This morphology trend is in good agreement with the decrease in fatigue life of NR/BR compounds. Although the fatigue life is decreased, the image showed surfaces in region 'II' of MRP-filled are much rougher compared to the control compound. It is presumed that the presence of MRP could provide additional energy dissipation and thus prevent catastrophic failure.

\section{CONCLUSIONS AND FUTURE STUdY}

The SEM images of the fracture surface of the control rubber compound and their MRP-filled materials after the fatigue test showed variable textures dependent on rubber phase/ratio and particle size concentration. The incorporation of MRP particle into the rubber matrix led to increase in fracture surface roughness. The rougher morphology of MRP-filled BR correlated well to the improvement in the fatigue life of the rubber compounds. This also showed that MRP particles are well bonded in the BR matrix. In MRP-filled NR and NR/BR, the fatigue life was reduced significantly at $30 \mathrm{pphr}$. However the transition from smooth to rough in surface fracture morphology showed advantages 
of preventing catastrophic failure.

Under various stress-strain conditions, micro-crack initiation due to inherent flaws or MRP addition leads to crack propagation and eventually failure. Therefore, crack growth resistance of rubber containing recycled rubber particles are great importance in determining the strength and durability of rubber products and this is our future scope of study.

\section{ACKNOWLEDGMENT}

The authors appreciate the mixing assistance from Jonathan Clark and Paul Gladwin; Sarah Moazami, Ruth Barnett, Cath Zouine and Glynis Mewitt for mechanical testing; Vincenzo Orlando and Robert Picken for fatigue test setup; Terry Richards for confocal microscopy and Peter Bond in SEM preparation.

\section{REFERENCES}

[1] S. Ramarad, M. Khalid, C. T. Ratnam, A. L. Chuah, and W. Rashmi, "Waste tire rubber in polymer blends: A review on the evolution, properties and future," Prog. Mater Sci., vol. 72, pp. 100-140, 2015.

[2] P. J. Van Beukering and M. A. Janssen, "Trade and recycling of used tyres in Western and Eastern Europe," Resources, Conservation and Recycling, vol. 33, pp. 235-265, 2001.

[3] M. Forrest. Recycling and re-use of waste rubber 2015. (November 6, 2016). Overview of the World Rubber Recycling Market. [Online]. Available: http://www.smithersrapra.com/publications/books

[4] F. P. Papp, "Optimizing the use of micronized rubber powder made from end-of-life tire material," Rubber World, vol. 246, pp. 16-27, 2012.

[5] R. Ayyer, T. Rosenmayer, W. Schreiber, and J. Colton, "Effects of micronized rubber powders on structure and properties of polypropylene composites," Waste and Biomass Valorization, vol. 4 , pp. $65-71,2013$.

[6] S. Kamaruddin, Long-Term Mechanical Properties of ruBber, University of Southampton, 2013.

[7] C. L. Smith, "Basic confocal microscopy," Current Protocols in Neuroscience, vol. 2, no. 2, pp. 1-13, 2011.

[8] W. Dierkes, "Untreated and treated rubber powder," Rubber Recycling, pp. 127-154, 2005.

[9] D. Gibala, D. Thomas, and G. Hamed, "Cure and mechanical behavior of rubber compounds containing ground vulcanizates: part II. Tensile and tear strength," Rubber Chem. Technol., vol. 72, pp. 357-360, 1999.

[10] D. Gibala and G. R. Hamed, "Cure and mechanical behavior of rubber compounds containing ground vulcanizates. Part I-Cure behavior," Rubber Chem. Technol., vol. 67, pp. 636-648, 1994.

[11] A. Phadke, S. Chakraborty, and S. De, "Cryoground rubber-natural rubber blends," Rubber Chem. Technol., vol. 57, pp. 19-33, 1984.

[12] S. Bandyopadhyay, S. Dasgupta, S. Agrawal, and S. Mandot, "Use of recycled tyre material in NR/BR blend based tyre tread compound: Part II (with ground crumb rubber)," in Proc. Progress in Rubber, Plastics and Recycling Technology, 2006, vol. 22, p. 269.

[13] S. Beurrot, B. Huneau, and E. Verron, "In situ SEM study of fatigue crack growth mechanism in carbon black-filled natural rubber," $J$. Appl. Polym. Sci., vol. 117, pp. 1260-1269, March 2010.

[14] L. Munoz, L. Vanel, O. Sanseau, P. Sotta, D. Long, L. Odoni, and L. Guy, "Fatigue crack growth dynamics in filled natural rubber," Plastics, Rubber and Composites, vol. 41, pp. 273-276, 2012.
[15] K. Agarwal, D. Setua, and K. Sekhar, "Scanning electron microscopy study on the influence of temperature on tear strength and failure mechanism of natural rubber vulcanizates," Polym. Test., vol. 24, pp. 781-789, 2005.

[16] P. Pal and S. De, "Studies of polymer-filler interaction, network structure, physical properties, and fracture of silica-and clay-filled epdm rubber in the presence of a silane coupling agent," Rubber Chem. Technol., vol. 56, pp. 737-773, 1983.

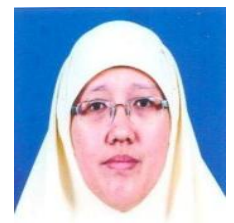

Dayang Habibah A. I. H. is a research officer of Malaysian Rubber Board, Malaysia. She was born in Malaysia. She obtained her B.Sc. in material science from University Kebangsaan Malaysia and M.Phil from Loughborough University, UK on flame retardant rubber research. She is currently pursuing $\mathrm{PhD}$ in University of Plymouth. Her research area is in the mechanical and fatigue properties of compound containing recycled powder from waste tyres.

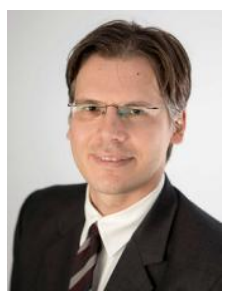

Frank Abraham is an associate professor in mechanical and marine engineering at the School of Engineering, University of Plymouth. He is teaching, conducting research and development projects in the fields of engineering materials and design. He was the associate head in engineering of the School of Marine Science and Engineering at University of Plymouth, until recently where he was responsible for the Mechanical \& Marine Engineering subject group and overseeing the Civil and Coastal Engineering group. He has previously worked at the University of Portsmouth, University of Oxford, St Anne's College and St Hilda's College, University of Oxford, University of Dundee, Automotive Competence Centre of the Hochschule Heilbronn, Germany, Deutsches Institut für Kautschuktechnologie e.V., DIK, Hannover and the University of Applied Sciences and Arts Hannover, Germany.

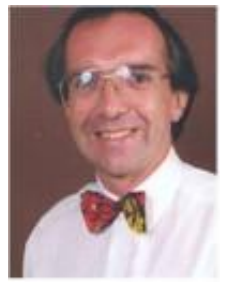

John Summerscales has BSc (joint honours) in applied sciences (pure and applied chemistry/polymer science and technology) from Cardiff University, MSc in molecular science of materials from University of Greenwich, and PhD hybrid composites/pgdiped from the university of plymouth. He is a professor of composites engineering at the University of Plymouth and Chartered Engineer, Chartered Environmentalist and Chartered Scientist.

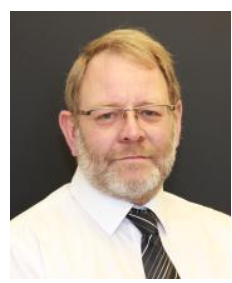

Paul Brown has been at TARRC for nearly 35 years After studying Natural Sciences at University. During this time he has worked in rubber chemistry, dry rubber applications and physical testing before becoming the head of the Materials Development Unit in 2007. His areas of interest include the distribution of materials between the rubber phases of a blend, both due to thermodynamics and mixing, applications. crosslinking and properties and, more recently, tyre 